\title{
EDITORIAL METHOD
}

The translations in this book are based on fresh revision of the ancient texts. Before translating any text I have critically reviewed the variants reported in the best modern edition. In the case of texts preserved in Coptic, I have also compared them with the manuscript or manuscripts in photographic facsimile. If a text has survived in two ancient languages, I have examined both versions, though the Syriac version of HPrl has not been restudied in detail. Any textual revisions that seemed necessary have been adopted silently, since the plan of this book does not permit philological notes. Colleagues in textual criticism can easily spot these changes by comparing my translation with the critical edition cited in the introduction to the work.

As editor-translator I viewed my task as being threefold:

1. where the manuscript was physically damaged, to ascertain whether or not the missing text could be restored with certainty;

2. to discover any ancient copyist's errors in the manuscript (there are always some) and if possible to correct them, or to accept a correction already proposed by some modern critic;

3. to ensure that Greek literary, rhetorical, and philosophical traditions were taken into account in translating the text into English.

My aims as I performed these three tasks were the following:

1. to adopt a factual approach to the restoration of lacunae, rejecting mere speculation and admitting only restorations that are certain (always enclosed in square brackets [ ]);

2. to recompare carefully the details and systems of related gnostic myths - which has sometimes led me to reject modern critics' emendations in favor of the received reading of one of the manuscripts;

3. to be flexible in translating from the ancient Coptic, taking account of the text's original composition in Greek as a product of Hellenistic-Roman culture. 
Needless to say, I am deeply dependent on the editorial research of my predecessors, who for the most part established the original text of these works.

I have used square brackets [ ] conservatively; often a word enclosed in brackets is significantly intact in the manuscript and so is virtually a preserved reading. 